\title{
Seizure Recurrence in Rural Zambian Children Admitted with Febrile Seizures
}

\author{
Elwyn Chomba ${ }^{1}$, Terrie E. Taylor ${ }^{2}$, W. Hauser ${ }^{3}$, Claude Wasterlain ${ }^{4}$, Natalie Organek ${ }^{2}$ and \\ Gretchen Birbeck ${ }^{2,5, *}$ \\ ${ }^{1}$ Lusaka Zambia; ${ }^{2}$ East Lansing, MI, United States; ${ }^{3}$ New York, NY, United States; ${ }^{4}$ Los Angeles, CA, United States and \\ ${ }^{5}$ Mazabuka, Zambia
}

\begin{abstract}
Background: Long-term outcomes following febrile seizures in African children are not well described, but malaria-associated seizures are a risk factor for epilepsy.

Design/Methods: 107 consecutive children admitted with febrile seizures (FS group) were age-matched to concurrently admitted children with febrile illness and no seizure, or febrile illness only (FIO). Quarterly follow-up assessments determined interim seizures and developmental outcomes.

Results: 214 children were enrolled and followed for mean 20.4 months (median 24, mode 27). The most common diagnosis was clinical malaria. During follow-up, children in the FS group were more likely to have recurrent febrile seizures (29.9 vs. 11.3\%; RR1.27; CI 1.10-1.46), an unprovoked seizure (27.1 vs. 1.9\%; RR 1.35; CI 1.20-1.52) and epilepsy (11.2 vs. 0.9 ; RR 1.16; CI 1.04-1.20). Risk factors for unprovoked seizures during follow-up included younger age at enrollment ( 25.5 v. 34.6 months, $\mathrm{p}=0.04$ ) and developmental delay preceding the index illness (33.3 vs. $13.1 \%, \mathrm{p}=0.009)$.

Within the FS group, children with focal seizures at enrollment were more likely to experience unprovoked seizures (52.9 vs. $20 \%$, $\mathrm{p}=0.007)$ and epilepsy ( 41.7 vs. $7.8 \%, \mathrm{p}=0.03)$.

Conclusions: Children admitted with febrile seizures in rural Zambia have a high risk of subsequent epilepsy. Further research is needed to determine if specific infectious etiologies (e.g. malaria) are associated with epilepsy development in such children. Where access to healthcare services are limited, febrile seizure admission may also be a marker for a preexisting propensity toward later epilepsy. Regardless, follow- up is warranted to facilitate early initiation of treatment if recurrent, unprovoked seizures occur.
\end{abstract}

Key Words: Malaria, febrile convulsions, epilepsy, developmental delay, The Ten Questions.

\section{INTRODUCTION}

Febrile seizures contribute to a significant burden of disease in children under five in developing countries [1-3]. A study in Nigeria found that $20 \%$ of pediatric admissions during a 9-month observation period were for febrile seizures. Common causes for fever included malaria $(32 \%)$ and pneumonia (16\%) [1] . Malaria remains a major public health problem in Zambia, accounting for nearly $40 \%$ of all outpatient attendances, 50\% among children under-five [4]. Malaria incidence rates in Zambia have tripled over the past three decades, from 121/1,000 in 1976 to 396/1,000 in 2003. Many factors have led to this increase, including the spread of chloroquine resistance, reduced vector control activities, and decreased access to quality care.

The risk of developing epilepsy following a febrile seizure has been well studied in US and UK populations [5-8]. In developed countries, simple febrile seizures predominate and do not warrant long-term interventions [9]. In contrast, fever-associated seizures in malaria endemic regions are often complicated. A hospital-based study in Kenya found

*Address correspondence to this author at the Michigan State University, \#324 West Fee Hall, East Lansing, MI 48824, USA; Tel: +1-517-884-0277; Fax: +1-517-884-0275; E-mail: Gretchen.Birbeck@ht.msu.edu
$84 \%$ of children with malarial fevers and seizures had complex seizures with $47 \%$ being focal and over $70 \%$ repetitive [10]. Cerebral malaria (meaning asexual $P$. falciparum parasitemia, coma persisting for more than two hours after a seizure, and no other etiology for fever evident) and malariaassociated seizures without coma were identified as risk factors for epilepsy in a retrospective cohort study in Kenya [11]. The burden of epilepsy in older children living in rural Kenya is also associated with a family history of epilepsy and a history of febrile seizures [5]. No prospective, population-based studies of febrile seizure outcomes have been conducted in less developed, tropical settings where fevers from malaria are common.

We conducted a prospective, exposure control study among children hospitalized with febrile seizures in rural Zambia to assess the risk of recurrent febrile seizures, unprovoked seizures and epilepsy in this population.

\section{MATERIALS AND METHODS}

\section{Study Location}

Chikankata Hospital is located approximately 30 kilometers off a major road in the southern province of Zambia. The local Zambian population served by Chikankata consists 
almost entirely of subsistence farmers. Over $80 \%$ of people live in traditional housing (mud brick huts with thatch roof) without electricity. P. falciparum is endemic in the region with peak infection rates corresponding to rainy season (December-March annually).

\section{Study Population}

During three consecutive recruitment periods JanuaryMarch in 2003-2005, a daily review of the Outpatient Department admission roster was completed. The study team also reviewed admissions lists for the Pediatric Ward, Mothers and Babies Ward, and Intensive Care Unit daily. These are the only wards that admit patients between 6 months and 6 years of age. During recruitment, children brought to Chikankata Hospital with a seizure and a fever were admitted for at least 24 hours observation.

Febrile children (6 months- 6 years old) admitted with a history of seizure within 12 hours of admission or a seizure during their admission were eligible for enrollment. "Febrile" was defined as having a temperature of $>38.5$ degrees Celsius. Children with a history of unprovoked seizures or head trauma significant enough to cause loss of consciousness were excluded. Lumbar punctures were completed when clinically indicated and children with cerebrospinal fluid (CSF) abnormalities were excluded. Children in coma, defined as a Blantyre Coma Score of less then three more than 1 hour after the last witnessed seizure, were excluded. For study follow-up purposes, children who resided outside of the Chikankata catchment area were not eligible for enrollment. Previous record review indicated that less than $3 \%$ of children under-five who present for care come from outside the Chikankata district. Children with a history of febrile seizures prior to the index illness were eligible.

Unexposed control subjects were children with febrile illness only (FIO) identified from concurrently hospitalized children age (+/- 6 months) matched to the FS population. The same exclusion criteria were applied. For each FS child enrolled, a FIO subject was matched using the next eligible child admitted who met matching criteria and whose parents consented to enrollment.

Community health workers (CHW) at Chikankata are routinely consulted for village illnesses and often act as the advocate for patients requiring urgent clinic or hospital evaluation. To optimize community-based documentation of interim health events, $\mathrm{CHWs}$ from each village participated in a 2-day teaching session at Chikankata prior to the initiation of this work.

This work was approved by the University of Zambia's Research Ethics Committee and Michigan State University's Biomedical IRB.

\section{Data Collection: Hospital Admission}

Standardized registration forms, which included age, gender, febrile seizure type (focal vs. generalized), fever etiology (malaria vs. other), clinical diagnosis (as per the physician), malaria parasitemia, and temperature at admission, were completed by the attending physician for all children from 6 months to 6 years of age who presented to Chikankata with a seizure and a fever during the enrollment periods. Exclusion criteria were reviewed and caregivers of qualifying subjects were approached for consent by research staff within 24 hours after the child's admission.

Among study subjects, additional variables including maximum temperature during admission, family seizure history, birth history, mother's level of education, home village proximity to the hospital categorized into 4 zones, and any seasonal relocation sites were collected. Details regarding the febrile seizure (focality, duration, number of seizures) were also sought. Children were screened for developmental abnormalities using The Ten Questions Screen. This instrument has been shown to be valid in children as young as two years [12] and has been evaluated in resource poor settings demonstrating good reliability $(\mathrm{kappa}=0.67)$ with $85 \%$ sensitivity for detecting severe neurodevelopmental disabilities [13]. The Ten Questions were forward and back translated into the local language with discrepancy resolution prior to use.

Before discharge, a full neurologic examination was conducted and recorded on a standardized exam form. Nutritional status including weight, height and mean upper arm circumference was determined just prior to discharge to avoid taking weight measurements in dehydrated children. World Health Organization (WHO) standards for categorizing children as "underweight" were used.

The diagnostic capacity available during the acute admission reflected those resources generally available in such settings. Specifically, EEGs were not available. Thick blood films for malaria diagnosis were reviewed, but those data were not included in this analysis because (a) specimens were often taken $>24$ hours after treatment with antimalarials in children admitted in the evenings or on the weekends, and (b) substitution of accepted standards for blood smear assessment including a decrease in the number of high power fields reviewed from 100 to 10 , poor quality Giemsa stain and deviation from buffering protocols, made external quality checks impossible at times and when quality checks were possible indicated sub-optimal interpretation of the available slides. Such problems have been reported in other Africabased studies of malaria [14]. Lumbar puncture and CFS analysis were limited to basic studies (glucose, protein, cell count, differential, gram stain, India ink). Neuroimaging was not available.

Given the imperfect nature of malaria diagnosis and the potential adverse consequences of untreated malaria in young children, among children admitted with fever, malarial treatment is initiated unless/until the peripheral smear result is reported negative. Even if the smear is negative, if clinical suspicion remains high treatment is continued and completed. Only those children with a clear other source of fever, no clinical signs of malaria (anemia, hepatosplenomegaly), and a negative malarial smear have antimalarial treatment discontinued.

\section{Data Collection: Longitudinal Follow-up}

Based upon parental preference, study children returned quarterly to the hospital or were visited in their homes by the mobile research team. The research nurse completed a follow-up assessment form that included information for any of the following events; [1] Interim febrile seizures as determined by interviews with the caregiver and community health worker $(\mathrm{CHW})$, and by review of the outpatient medi- 
cal record [2] interim unprovoked seizure as determined by interviews with the caregiver and community health worker, and by review of the outpatient medical record, and [3] evidence of chronic or acute illness as determined by the study nurse. Children visited at home were offered transportation to Chikankata Hospital for physician assessment, if deemed necessary by the study nurse. When loss to follow-up occurred, the study nurse interviewed the appropriate $\mathrm{CHW}$ to determine cause (e.g.--relocation, death). Parents who brought the child to the hospital for quarterly reviews were reimbursed for travel costs and lunch.

\section{DATA ANALYSIS}

\section{Cross Sectional Analysis of Admission Characteristics}

To assess for risk factors associated with presenting with a febrile seizure vs. a febrile illness without seizure, chisquare and t-test comparisons were made between the FS and FIO groups on demographic data, medical histories, and acute clinical characteristics. A multivariate logistic model was also developed with the dependent variable of FS vs. FIO and independent variable including demographic data, medical histories, and acute clinical characteristics.

Within the FS group, factors associated with experiencing simple versus complex febrile seizures were determined using chi-square and t-tests comparisons of demographic data, medical histories, and acute clinical characteristics.

\section{Longitudinal Outcomes}

We compared the rate of recurrent febrile seizures, unprovoked seizure, epilepsy and new developmental abnormalities in the FS exposed vs. FIO groups using the chisquare test.

To assess for risks of unprovoked seizure, chi-square and t-tests were used comparing demographic data, medical histories, and acute clinical characteristics in the combined FIO and FS populations. A multivariate logistic model with the dependent variable being "unprovoked seizure(s) during follow-up" vs. "no unprovoked seizures during follow-up" was also developed, which included characteristics found in other reports to be associated with the risk of epilepsyspecifically age at FS presentation, a history of an abnormal developmental screen, family history of seizures, malaria as the etiology for the febrile seizure and duration of follow-up. We also compared the incidence of new developmental delay and recurrent febrile seizures during follow-up in the "unprovoked seizure during follow-up" vs. "no unprovoked seizure during follow-up" groups.

\section{RESULTS}

During recruitment, 214 children were enrolled and followed for mean 20.4 months (median 24, mode 27). There were no differences in follow-up duration or loss-to-followup ( 2 children in each group) between the FS and FIO groups. One child died at home during the study of a diarrheal illness. Incomplete admission data was captured for one control subject, requiring exclusion from the analysis. The most common diagnosis was clinical malaria.

Table 1 illustrates descriptive characteristics of the FS vs. FIO groups at the time of enrollment. There were no differences on age, gender, residential proximity to the hospital, birth history, or mothers' level of education. Children with febrile seizures were more likely to have a personal history of febrile seizures (30.8 vs. 6.6\%; OR 6.31; CI 2.64-15.04), a family history of febrile seizures (11.2 vs. $1.9 \%$; OR 6.57 ; CI $1.43-30.12)$, a family history of epilepsy (14.0 vs. $4.7 \%$; OR 3.29 ; CI 1.15-9.42), a history of developmental abnormalities prior to the index illness (36.4 vs. $11.3 \%$; OR 4.55 (2.199.22) and a clinical diagnosis of malaria (81.3 vs. $63.2 \%$; OR 2.53; CI 1.35-4.74).

In the multivariate model, a history of febrile seizure (OR 7.71; CI 2.92-20.32), a family history of febrile seizure (OR 5.44; CI 1.09-27.15) and a clinical diagnosis of malaria (OR 3.18; CI 1.46-6.95) remained significant (see Table 2).

Within the FS group, most children had been febrile by parental report for 1 day or less before presenting to the hospital. The majority of febrile seizures $(68.2 \%)$ were complex febrile seizures $-61.7 \%$ of children experienced more than one seizure during the febrile illness with $13.1 \%$ experiencing more than 4 witnessed seizures. Most seizures were brief with $71.0 \%$ being < 5 minutes duration. Seizure focality was noted in $15.9 \%$ of FS cases. See Table 3. Complex vs. simple febrile seizures were compared on demographic characteristics, medical history and clinical presentation (see variables from Table 1). In chi-square and t-test analysis, complex febrile seizures were associated with lower maternal education (4.4 vs. 5.9 years; $\mathrm{p}=0.012$ ) and a clinical diagnosis of malaria (86.3 vs. 70.6\%; OR 1.81; CI 1.04-3.16). Rates of parasitemia were not different between the complex and simple febrile seizure groups.

During follow-up, children in the FS group were more likely to experience recurrent febrile seizures (29.9 vs. $11.3 \%$; RR 1.27; CI 1.10-1.46), at least one unprovoked seizure (11.2 vs. 1.9\%; RR 1.35; CI 1.20-1.52) and epilepsy (11.2 vs. $0.9 \%$; RR 1.16; CI 1.04-1.20). There was no difference in developmental outcomes. See Table 4.

Characteristics associated with experiencing at least one unprovoked seizure during follow-up are illustrated in Table 5. These included developmental abnormalities at enrollment (33.3 vs. $13.1 \%$; RR2.63; p=0.009), younger age of enrollment (28.6 vs. 35.0 months; $\mathrm{p}=0.04$ ), and a longer mean duration of follow-up ( 24.2 vs. 19.7 months; $\mathrm{p}=0.006$ ). Children who experienced unprovoked seizures during follow-up had a higher incidence of new developmental delay (30.0 vs. $10.6 \%$; RR $1.28 ; \mathrm{p}=0.03$ ) and were also more likely to experience febrile seizures during follow-up (66.7 vs. 13.1\%; RR7.68; $\mathrm{p}<0.0005)$. In the multivariate model, these all remained significant (Table 6 ).

Among the FS group, characteristics of the index febrile seizures were examined to assess risk factors for later unprovoked seizure. Duration of fever, complex vs. simple febrile seizure, number of seizures and duration of seizures were not associated with later unprovoked seizures. In a post-hoc analysis, children who were enrolled with focal febrile seizures vs. generalized were more likely to experience unprovoked seizures (52.9 vs. $20 \%, \mathrm{p}=0.007)$ and epilepsy $(41.7$ vs. $7.8 \%, \mathrm{p}=0.03$ ) during follow-up.

\section{DISCUSSION}

In this prospective, exposure control study of febrile seizures in a resource poor, malaria endemic region of Zambia, 
Table 1. Characteristics of Children with Febrile Seizure (FS) vs. Febrile Illness Only (FIO) (N=213)

\begin{tabular}{|c|c|c|c|}
\hline Demographics & FS & FIO & OR $(95 \% \mathrm{CI})$ or $\mathrm{p}$-Value \\
\hline \multicolumn{3}{|l|}{ Age at enrollment (months) } & \multirow[t]{3}{*}{$\mathrm{P}=0.81$} \\
\hline Median & 30.0 & 31.0 & \\
\hline Mode & 36.0 & 48.0 & \\
\hline Male (n, \%) & $67(62.6 \%)$ & $54(50.9 \%)$ & $1.61(0.93-2.79)$ \\
\hline Proximity to hospital (zone $1^{1}$ vs. others) & $44(41.1 \%)$ & $56(52.8 \%)$ & $0.62(0.36-1.07)$ \\
\hline \multicolumn{3}{|l|}{ Mother's education (years) } & \multirow[t]{2}{*}{$\mathrm{P}=0.14$} \\
\hline Range & $0-12$ & $0-11$ & \\
\hline \multicolumn{4}{|l|}{ Medical History } \\
\hline Delivery by tba $^{2}(\mathrm{n}, \%)$ & $63(58.9 \%)$ & $54(50.9 \%)$ & $1.38(0.80-2.37)$ \\
\hline Did not cry at birth (n, \%) & $6(5.7 \%)$ & $2(1.9 \%)$ & $3.12(0.62-15.83)$ \\
\hline Febrile seizure history $(\mathrm{n}, \%) *$ & $33(30.8 \%)$ & $7(6.6 \%)$ & $6.31(2.64-15.04)$ \\
\hline Family history of febrile seizure (n, \%)* & $12(11.2 \%)$ & $2(1.9 \%)$ & $6.57(1.43-30.12)$ \\
\hline Family history of epilepsy $(\mathrm{n}, \%)^{*}$ & $15(14.0 \%)$ & $5(4.7 \%)$ & $3.29(1.15-9.42)$ \\
\hline Median & 40.0 & 40.0 & \multirow{3}{*}{$\mathrm{P}=0.26$} \\
\hline Mode & 40.0 & 40.0 & \\
\hline Range & $38.0-41.0$ & $38.0-42.0$ & \\
\hline Underweight for age & $40(37.4 \%)$ & $38(36.5 \%)$ & $1.04(0.59-1.81)$ \\
\hline
\end{tabular}

${ }^{1}$ Zone 1 includes villages immediately adjacent to the hospital, usually less than $5 \mathrm{~km}$. Zones $2-4$ are more distant and have additional geographic barriers including streams; ${ }^{2}$ tba $=$ traditional birth attendant vs. midwife or physician; ${ }^{3}$ Historical 10 Question screen.

* Statistically significant variables.

children presenting to a rural hospital with febrile seizures frequently experienced complex febrile seizures and were at high risk of later unprovoked seizures and epilepsy. Within three years, 1 in 4 children experienced an unprovoked seizure and 1 in 10 had developed epilepsy.

Malaria was the most commonly diagnosed fever etiology in febrile children during the observation period and a clinical diagnosis of malaria was more common in the FS group. However, objective laboratory-based measures of malaria parasitemia were not available due to issues with specimen collection and sub-optimal laboratory standards during the time of this study. The lack of objective quality laboratory data regarding malaria parasitemia is a limitation of this work, but reflects the realities of clinical care in this setting and does not detract from the outcomes found among children admitted with febrile seizures.

An additional limitation of this study is that the population included only children who were brought into the hospital for care during their acute febrile illness. This is not a population-based sample and subsequent seizures during follow-up in the FS group may indicate that these children had a propensity toward seizure prior to their index illness. 
Indeed, a pre-existing propensity toward seizure is supported by the higher frequency of pre-existing development delay and familial seizures in the FS population at the time of enrollment. As a hospital-based study in a resource poor, rural region the children presenting for care likely represent a more severe end of the illness spectrum. We know from our experience in this follow-up study that many parents do not bring their children in for care if the child has "body hotness" and a brief seizure, particularly if the child wakes up quickly and appears to be back to normal.

Table 2. Multivariate Logistic Model of Febrile Seizure (FS) vs. Febrile Illness Only (FIO) $(n=213)$

\begin{tabular}{|c|c|}
\hline Variable & OR $(95 \% \mathrm{CI})$ \\
\hline \multicolumn{2}{|l|}{ Demographics } \\
\hline Age (months) & $1.00(0.98-1.02)$ \\
\hline Gender $($ male $=1)$ & $1.30(0.69-2.45)$ \\
\hline Mother's education (years) & $0.97(0.87-1.09)$ \\
\hline Proximity to hospital & $0.78(0.40-1.52)$ \\
\hline \multicolumn{2}{|l|}{ Medical History } \\
\hline Delivery mode (tba vs. other) & $1.07(0.55-2.07)$ \\
\hline Cried at birth (yes vs. no) & $0.29(0.05-1.90)$ \\
\hline Febrile seizure history* & $7.71(2.92-20.32)$ \\
\hline Family history of febrile seizure* & $5.44(1.09-27.15)$ \\
\hline Family history of epilepsy & $2.89(0.86-9.56)$ \\
\hline \multicolumn{2}{|l|}{ Clinical Characteristics } \\
\hline Clinical diagnosis of malaria ${ }^{1, *}$ & $3.18(1.46-6.95)$ \\
\hline Max temp (Celsius) & $1.06(0.70-1.60)$ \\
\hline Underweight (yes) & $1.21(0.62-2.36)$ \\
\hline
\end{tabular}

'Parasitemia (present vs. absent) was not significant when placed in the model instead of clinical diagnosis of malaria.

* Statistically significant variables.

Prior research has established that longer periods of active epilepsy without treatment are associated with higher rates of seizure-related injury from burns and falls [3], poorer educational opportunities for children [15] , and greater epilepsy-associated disability [16]. Given the high risk of epilepsy among children who present with febrile seizures in this resource poor, malaria endemic region, long-term follow up is warranted to assure that anticonvulsant medications are initiated if a chronic seizure disorder develops.

Table 3. Descriptive Characteristics of Febrile Seizure Cases $(\mathrm{n}=107)$

\begin{tabular}{|c|c|}
\hline Time with Fever before Seizure & $\mathbf{N}(\%)$ \\
\hline No fever noted & $1(0.9)$ \\
\hline$<1$ day & $52(48.1)$ \\
\hline$\sim 1$ day & $23(21.3)$ \\
\hline$>1$ day & $32(29.6)$ \\
\hline Complex Seizure & $73(68.2)$ \\
\hline \multicolumn{2}{|l|}{ Number of Seizures ${ }^{1}$} \\
\hline 1 & $41(38.3)$ \\
\hline 2 & $24(22.4)$ \\
\hline 3 & $20(18.7)$ \\
\hline 4 & $8(7.5)$ \\
\hline$>4$ & $14(13.1)$ \\
\hline \multicolumn{2}{|l|}{ Length of Seizure } \\
\hline$<5$ minutes & $76(71.0)$ \\
\hline 5-15 minutes & $13(12.1)$ \\
\hline $15-30$ minutes & $4(3.7)$ \\
\hline$>30$ minutes & $14(13.1)$ \\
\hline Focal Seizures & $17(15.9)$ \\
\hline
\end{tabular}

${ }^{1}$ During the index febrile illness.

\section{ACKNOWLEDGEMENTS}

Funded by Charles E. Culpeper Medical Scholar Program through the Goldman Philanthropic Partnerships and NIH NS46086.

We thank Chieftainess Mwenda for her support in conducting this work as part of her dedicated advocacy work to improve the lives of people with epilepsy in Zambia. Many thanks also to the Chikankata Epilepsy Care Team, especially Ms. Fridah Kabwenda and Mr. Charles Mabeta, for their dedicated efforts in conducting this study.

Table 4. Outcomes in Febrile Seizure (FS) vs. Febrile Illness Only (FIO) Groups During Follow-Up

\begin{tabular}{|c|c|c|c|}
\hline Recurrent febrile seizures* & $32(29.9)$ & $12(11.3)$ & $1.27(1.10-1.46)$ \\
\hline Epilepsy* & $12(11.2)$ & $1(0.9)$ & $1.16(1.04-1.20)$ \\
\hline New developmental delay abnormality & $16(15.0)$ & $8(7.5)$ & $1.09(.099-1.20)$ \\
\hline
\end{tabular}

* Statistically significant variables. 
Table 5. Factors Associated with Unprovoked Seizures During Follow-Up $(n=213)$

\begin{tabular}{|c|c|c|c|}
\hline Demographics & Unprovoked Seizure(s) & No Unprovoked Seizures & $p=$ Value \\
\hline \multicolumn{3}{|l|}{ Age at enrollment (months) } & \multirow[t]{5}{*}{$\mathrm{P}=0.04^{*}$} \\
\hline Mean & 28.6 & 35.0 & \\
\hline Median & 26.5 & 31.0 & \\
\hline Mode & 16.0 & 48.0 & \\
\hline Range & $12-63$ & $6-70$ & \\
\hline Male $(\mathrm{n}, \%)$ & $15(50 \%)$ & $106(57.9 \%)$ & $0.76(\mathrm{p}=0.27)$ \\
\hline Proximity to hospital (zone 1 vs. 2-4) & $12(40.0 \%)$ & $88(48.1 \%)$ & $0.75(\mathrm{p}=0.27)$ \\
\hline \multicolumn{3}{|l|}{ Mother's education (years) } & \multirow[t]{5}{*}{$\mathrm{P}=0.53$} \\
\hline Mean & 5.5 & 5.1 & \\
\hline Median & 6.0 & 6.5 & \\
\hline Mode & 7.0 & 7.0 & \\
\hline Range & $0-12$ & $0-12$ & \\
\hline Duration of follow-up (mean months)* & 24.2 & 19.7 & $\mathrm{P}=0.006$ \\
\hline \multicolumn{4}{|l|}{ Medical History } \\
\hline Delivery by tba ${ }^{1}(\mathrm{n}, \%)$ & $18(60 \%)$ & $99(54.1 \%)$ & $1.23(\mathrm{p}=0.34)$ \\
\hline Did not cry at birth $(\mathrm{n}, \%)$ & $1(3.3 \%)$ & $7(3.8 \%)$ & $0.88(\mathrm{p}=0.69)$ \\
\hline Febrile seizure history $(\mathrm{n}, \%)$ & $7(23.3 \%)$ & $33(18.0)$ & $1.32(\mathrm{P}=0.32)$ \\
\hline Family history of febrile seizure (n, \%) & $3(10.0 \%)$ & $11(6.0 \%)$ & $1.58(\mathrm{p}=0.31)$ \\
\hline Family history of epilepsy (n, \%) & $3(10.0 \%)$ & $17(9.3 \%)$ & $1.07(\mathrm{p}=0.56)$ \\
\hline Abnormal 10 Question Screen at Enrollment (n, \%)* & $10(33.3 \%)$ & $2(13.1)$ & $2.63(\mathrm{p}=0.009)$ \\
\hline \multicolumn{4}{|l|}{ Clinical Characteristics } \\
\hline Clinical Diagnosis (malaria) & $24(80.0 \%)$ & $130(71.0 \%)$ & $1.53(\mathrm{p}=0.22)$ \\
\hline \multicolumn{3}{|l|}{ Maximum temp (Celsius) } & \multirow[t]{5}{*}{$\mathrm{P}=0.99$} \\
\hline Mean & 39.6 & 39.6 & \\
\hline Median & 40.0 & 40.0 & \\
\hline Mode & 40.0 & 40.0 & \\
\hline Range & $38.0-41.0$ & $38.0-42.0$ & \\
\hline Underweight for age & $13(43.3 \%)$ & $65(35.9 \%)$ & $1.30(\mathrm{p}=0.28)$ \\
\hline Abnormal exam at discharge & $5(16.7 \%)$ & $14(7.8)$ & $2.01(\mathrm{p}=0.11)$ \\
\hline \multicolumn{4}{|l|}{ Incident neurologic outcomes } \\
\hline New developmental delay ${ }^{2, *}$ & $6(20.0 \%)$ & $15(10.6 \%)$ & $1.28(\mathrm{p}=0.03)$ \\
\hline Febrile Seizure ${ }^{3, *}$ & $20(66.7 \%)$ & $24(13.1 \%)$ & $7.68(\mathrm{p}<0.0005)$ \\
\hline
\end{tabular}

${ }^{1}$ tba=traditional birth attendant vs. midwife or physician.

${ }^{2}$ Excluded those with developmental delay by historical 10 question screen on admission $(n=162)$

${ }^{3}$ Febrile seizure prior to unprovoked seizure.

* Statistically significant variables. 
Table 6. Multivariate Logistic Model for Unprovoked Seizure During Follow-Up (n=213)

\begin{tabular}{|c|c|c|}
\hline Variable & OR $(95 \%$ CI $)$ & p-value \\
\hline \multicolumn{3}{|l|}{ Demographics } \\
\hline Age (months)* & $0.96(0.92-0.99)$ & 0.02 \\
\hline \multicolumn{3}{|l|}{ Medical History } \\
\hline Abnormal developmental screen at enrollment* & $3.30(1.29-8.47)$ & 0.01 \\
\hline Febrile seizure history & $1.45(0.52-4.07)$ & 0.48 \\
\hline Family history febrile seizure & $1.68(0.38-7.39)$ & 0.49 \\
\hline Family history epilepsy & $1.21(0.28-5.12)$ & 0.80 \\
\hline \multicolumn{3}{|l|}{ Clinical Characteristics } \\
\hline Clinical diagnosis (malaria vs. other) & $1.80(0.63-5.10)$ & 0.30 \\
\hline Duration follow-up (months)* & $1.27(1.06-1.53)$ & 0.01 \\
\hline
\end{tabular}

* Statistically significant variables.

\section{REFERENCES} [3] Birbeck GL. Seizures in rural Zambia. Epilepsia 2000; 41(3): 27781.

[4] CBOH. Annual Bulletin of the Health Information Managment System (HIMS). Lusaka, Zambia: Zambian Ministry of Health; 2003.

[5] Annegers JF. The Epidemiology of Epilepsy. In: Wylie E, Ed. The Treatment of Epilepsy: Principles and Practice. $2^{\text {nd }}$ ed. Baltimore: Williams \& Wilkins 1996. p. 165-72.

[6] Berg AT. Febrile seizures and epilepsy: the contributions of epidemiology. Paediatr Perinat Epidemiol 1992; 6(2): 145-52.

[7] Berg AT, Shinnar S. Unprovoked seizures in children with febrile seizures: short-term outcome. Neurology 1996; 47(2): 562-8.

[8] Berg AT, Shinnar S, Shapiro ED, Salomon ME, Crain EF, Hauser WA. Risk factors for a first febrile seizure: a matched case-control study. Epilepsia 1995; 36(4): 334-41.

[9] NIH Consensus Development summary. Febrile seizures: longterm management of children with fever-associated seizures [news]. South Med J 1980; 73(11): 1526.
[10] Waruiru CM, Newton CR, Forster D, et al. Epileptic seizures and malaria in Kenyan children. Trans R Soc Trop Med Hyg 1996; 90(2): 152-5.

[11] Carter JA, Neville BG, White S, et al. Increased prevalence of epilepsy associated with severe falciparum malaria in children. Epilepsia 2004; 45(8): 978-81.

[12] Durkin MS, Wang W, Shrout PE, et al. Evaluating a ten questions screen for childhood disability: reliability and internal structure in different cultures. J Clin Epidemiol 1995; 48(5): 657-66.

[13] Durkin MS, Hasan ZM, Hasan KZ. The ten questions screen for childhood disabilities: its uses and limitations in Pakistan. J Epidemiol Community Health 1995; 49(4): 431-6.

[14] Falade C, Mokuolu O, Okafor H, et al. Epidemiology of congenital malaria in Nigeria: a multi-centre study. Trop Med Int Health 2007; 12(11): 1279-87.

[15] Chomba E, Haworth A, Atadzhanov M, Mbewe E, Birbeck GL. The socioeconomic status of children with epilepsy in Zambia: Implications for long-term health and well-being. Epilepsy Behav 2008; 13: 620-3.

[16] Birbeck GL, Kalichi EM. The functional status of people with epilepsy in rural sub-Saharan Africa. J Neurol Sci 2003; 209(1-2): 65-8.

(C) Chomba et al.; Licensee Bentham Open.

This is an open access article licensed under the terms of the Creative Commons Attribution Non-Commercial License (http://creativecommons.org/licenses/ by-nc/3.0/) which permits unrestricted, non-commercial use, distribution and reproduction in any medium, provided the work is properly cited. 